\title{
Die Welt ohne uns
}

Alle vier Tage nimmt die Erdbevölkerung um eine Million Menschen zu. Migration und Urbanisierung machen die Welt zur Stadt. Würde ab heute jede Frau nur noch ein Kind gebären, dann wären um 2100 noch rund 1,6 Milliarden übrig, was der Bevölkerungszahl des beginnenden 19. Jahrhunderts entspricht. Dazu wird es nicht kommen. $\mathrm{Zu}$ was sonst? Alan Weisman, ein mehrfach ausgezeichneter amerikanischer Journalist, stellt die Frage anders: «Die Welt ohne uns» [1], wie sähe sie aus, wenn plötzlich alle Menschen verschwänden, einfach so? Ausser der Kopf- und Kleiderlaus wird uns niemand nachtrauern, das ist die Kernbotschaft des Buches. Oder weit wichtiger: Dem Planeten wird es ohne Homo sapiens ausgezeichnet gehen.

Das war zu vermuten, und fast könnte man auf diese Lektüre verzichten, wenn uns der Autor nicht auf eine wundersame Zeitreise mitnähme, faszinierende Orte besuchte und aus einer Menge Expertenwissen ein hervorragendes Sachbuch verfasst hätte. Er schildert mit handwerklicher Präzision, wie und wann ein Stadtteil wie Manhattan von der Natur zurückerobert wird, wie die Tierwelt sich erholt, Wälder sich wieder ausdehnen, wie $\mathrm{CO}_{2}$ ausgewaschen und die Ozeane wiederbelebt werden. Expeditionen mit Biologen, Botanikern, Geologen, Physikern und Archäologen eröffnen eine Forschungswelt, die zahlreiche Befunde einer geschichtlichen und geologischen Vergangenheit mit Entdekkungen der Gegenwart verknüpft. Warum ist die Megafauna Nordamerikas innerhalb von 1000 Jahren ausgestorben, warum verlief ihr Schicksal in Afrika anders? Warum sind Polymere unvergänglich, was geschieht mit den bereits über eine Milliarde Tonnen Kunststoffen und ihren Zugaben, die zum grössten Teil im Meer landen? Auch wenn eine nächste Eiszeit nachhilft, werden Spuren aus Kernkraftwerken, Schwermetallen im Boden, Ölanlagen und Chemiedeponien noch übrigbleiben und mit ihnen Bauwerke wie die antike Untergrundstadt in Kappadokien, Bunkeranlagen und die Tunnelröhren unter dem Kanal. Was für die Menschen eine Apokalypse, wäre für Land und Meer eine Verjüngungskur, eine Rückkehr ins Pleistozän, eine Neogenesis, wenn auch nicht mehr zurück zum Garten Eden. Viele Einwirkungen sind nicht mehr umkehrbar, tierische und pflanzliche Arten sind ausgerottet, neue Züchtungen und gentechnisch veränderte Organismen würden vielleicht die freien ökologischen Nischen besetzen. Bronzestatuen bleiben wundersam lange erhalten, und seit 1972 sind zwei Satelliten in galaktischen Tiefen mit einer Botschaft der Erdlinge unterwegs. Mit Diagrammen der DNS, Plänen des Sonnensystems, Fotografien, einem Kuss und einem Lachen und der Arie der Königin der Nacht aus Mozarts Zauberflöte. Die Voyager-Sonden werden uns überleben wie die Radiowellen, die eines Tages die Ränder des Universums erreichen.

Alan Weisman hält der technischen Zivilisation einen Spiegel vor, ein Memento mori, Reflexe einer posthumanen Welt. Nicht mehr Affen und schon gar keine Engel, sind wir uns und vor allem den nichtmenschlichen Wesen eine Katastrophe. Die Erde ist wunderschön, aber wir sind daran, sie kaputtzumachen. Das ist keine neue Erkenntnis; auch Kassandra sah richtig in die Zukunft, doch niemand glaubte ihr. Der Autor will uns mit einem Paradox aufrütteln, was der Kabarettist Hanns Dieter Hüsch auch schon vor Jahrzehnten wollte, als er sein «Posthum» textete: «Und Gott sprach zu den Wesen, die nun auf der Erde / sich tummelten / eigentlich ist es schade / denn der Mensch war mein Lieblingsspielzeug und / ich hatte meinen Gefallen an ihm / und vielleicht war es ein Fehler von mir / ihm zu gestatten eigene Wege zu gehen.» Sein Song verklingt sarkastisch, die posthumen Geier finden ein bekritzeltes Papier: «Kundgebung gegen die Umweltverschmutzung / kommt alle in Massen / es muss was geschehn / 20.15 Uhr Gemeindehaus ...»

Erhard Taverna

1 Alan Weisman. The World Without Us. New York: St Martin's Press; 2007. 324 Seiten. Deutsche Übersetzung: Die Welt ohne uns. München: Piper; 2007 (Übersetzung ohne Bilder). 